\title{
Elevated levels of serum CDCP1 in individuals recovering from severe COVID-19 disease
}

Jose-Ramon Blanco, ${ }^{1,2, *}$ María-Jesús Cobos-Ceballos ${ }^{3,4}$, Francisco Navarro ${ }^{5}$, Isabel Sanjoaquin ${ }^{6}$, Carlos Armiñanzas ${ }^{7}$, Enrique Bernal ${ }^{8}$, Luis Buzon-Martin ${ }^{9}$, Miguel Viribay ${ }^{10}$, Laura PérezMartínez ${ }^{2}$, Simona Espejo-Pérez ${ }^{3,11}$, Borja Valencia ${ }^{12}$, Jesus Guzman-Aguilar ${ }^{13}$, Juan-Jose RuizCubillan $^{14}$, Consuelo Alcalde ${ }^{15}$, Fernando Gustavo Gutierrez-Herrero ${ }^{16}$, Julian Olalla ${ }^{5}$, Eva-Maria Andres-Esteban ${ }^{17,18}$, Bernabe Jurado-Gamez ${ }^{3,4, *}$, Javier Ugedo ${ }^{19}$

${ }^{1}$ Servicio de Enfermedades Infecciosas, Hospital Universitario San Pedro, Logroño, La Rioja, Spain

${ }^{2}$ Centro de Investigación Biomédica de La Rioja, Logroño, La Rioja, Spain

${ }^{3}$ Instituto Maimónides de Investigación Biomédica de Córdoba, Universidad de Córdoba, Córdoba, Spain

${ }^{4}$ Servicio de Neumología, Hospital Universitario Reina Sofía, Córdoba, Spain

${ }^{5}$ Servicio de Medicina Interna, Hospital Costal de Sol, Marbella, Málaga, Spain

${ }^{6}$ Servicio de Enfermedades Infecciosas, HCU Lozano Blesa, Zaragoza, Spain

${ }^{7}$ Servicio de Enfermedades Infecciosas, H Universitario Marqués de Valdecilla, Santander, Spain

${ }^{8}$ Unidad de Enfermedades Infecciosas, Hospital General Universitario Reina Sofía de Murcia, Murcia, Spain

${ }^{9}$ Servicio de Medicina Interna, Hospital Universitario de Burgos, Burgos, Spain

${ }^{10}$ Vitro Laboratory, Madrid, Spain

${ }^{11}$ Servicio de Radiología, Hospital Universitario Reina Sofía, Córdoba, Spain

${ }^{12}$ Servicio de Neumología, Hospital Costal de Sol, Marbella, Málaga, Spain

${ }^{13}$ Servicio de Neumología, HCU Lozano Blesa, Zaragoza, Spain

${ }^{14}$ Servicio de Neumología, H Universitario Marqués de Valdecilla, Santander, Spain

${ }^{15}$ Servicio de Neumología, Hospital General Universitario Reina Sofía de Murcia, Murcia, Spain

${ }^{16}$ Servicio de Neumología, Hospital Universitario de Burgos, Burgos, Spain

${ }^{17}$ Grupo PBM, Instituto de Investigación-IdiPaz, Madrid, Madrid, Spain

${ }^{18}$ Universidad Rey Juan Carlos, Madrid, Madrid, Spain

${ }^{19}$ Servicio de Neumología, Hospital Universitario San Pedro, Logroño, La Rioja, Spain

*Equal contribution

Correspondence to: Jose-Ramon Blanco; email: jrblancoramos@gmail.com, https://orcid.org/0000-0002-4268-0150 Keywords: biomarkers, CDCP1, recovery COVID-19

Received: October 10, $2021 \quad$ Accepted: February 8, 2022 Published: February 16, 2022

Copyright: (c) 2022 Blanco et al. This is an open access article distributed under the terms of the Creative Commons Attribution License (CC BY 3.0), which permits unrestricted use, distribution, and reproduction in any medium, provided the original author and source are credited.

\section{ABSTRACT}

Background: COVID-19 survivors report residual lung abnormalities after discharge from the hospital. The aim of this study was to identify biomarkers in serum and induced sputum samples from patients after hospitalization for COVID-19.

Methods: Patients admitted to hospitals in Spain with laboratory-confirmed COVID-19 were recruited for this study. SARS-CoV-2-infected patients were divided into groups with mild/moderate and severe disease according to the severity of their symptoms during hospitalization. Levels of 92 biomarkers were measured in serum and induced sputum samples. 
Results: A total of 108 patients (46.2\% severe cases) were included in this study. The median number of days after the onset of symptoms was 104. A significant difference was observed in diffusing capacity for carbon monoxide (DLCO), an indicator of lung function, whereby DLCO $<80 \%$ was significantly lower in severe cases $(p<0.001)$. Differences in inflammatory biomarkers were observed between patients with mild/moderate and severe disease. For some biomarkers, correlations in serum and induced sputum levels were detected. Independent predictors of severe disease were DLCO $<80 \%$ and the serum CDCP1 value.

Conclusions: Higher levels of CDCP1 remain after hospital discharge and are associated with the severity of COVID-19. The possible prognostic implications warrant further investigation.

\section{INTRODUCTION}

According to the Johns Hopkins Coronavirus Resource Center, more than 156 million people worldwide have been infected with SARS-CoV-2 during the COVID-19 pandemic [1]. Although COVID-19 may cause multiple organ damage, pneumonia is the most frequent manifestation, ranging in severity from asymptomatic cases to cases of critical respiratory failure [2]. Furthermore, prospective studies have shown that the effects of COVID-19 continue after resolution of the symptoms of acute infection [3]. Thus, prospective studies related to outcomes following recovery from COVID-19 might improve our understanding of this disease, its sequelae, and possible interventions to improve this situation. Indeed, it is not well known whether the severity of the disease is associated with a persistent abnormal inflammatory state.

In other diseases caused by coronaviruses, such as severe acute respiratory syndrome (SARS) and Middle East respiratory syndrome (MERS), higher levels of proinflammatory cytokine were observed during the acute phase, and severe lung lesions developed $[4,5]$. In the current COVID-19 pandemic, residual lung abnormalities have been observed at 1-3 months after discharge from the hospital though information about serum inflammatory status during recovery from COVID-19 is limited. The identification of indicators of a post-COVID inflammatory state might improve the clinical management of these patients. Our objective was to assess a broad panel of markers in serum and induced sputum samples from individuals who had recovered from COVID-19; we compared the markers not only between groups but also between samples types.

\section{MATERIALS AND METHODS}

A description has been published elsewhere [6]. Briefly, this was a prospective study of patients older than 18 years who were admitted to different hospitals in Spain with COVID-19 confirmed by a real-time PCR (RTPCR) assay for SARS-CoV-2.
Patients were divided into groups based on whether they had had mild (including mild and moderate) or severe disease [7]. Patients who needed invasive mechanical ventilation were excluded because of its impact on systemic inflammation [8]. The epidemiological history, medical history, comorbidities, chronic treatments, and laboratory parameters of the patients were evaluated. Pulmonary function testing, the standardized 6-minute walk test (6MWT) [9] and chest-computed tomography (CT) were performed at least 45 days after symptom onset. CT findings were considered normal if groundglass opacities, the crazy-paving pattern, consolidation or linear opacities were absent [10].

The exclusion criteria included prior need for invasive mechanical ventilation, chronic infectious diseases, chronic lung diseases, concurrent autoimmune or malignant diseases, chronic use of corticosteroids or immunosuppressive therapies, pregnancy, alcohol/drug abuse, or a condition that did not allow participation in this study. The study was approved by the Institutional Research Ethics Committees. All participants provided written informed consent.

Serum samples were obtained from blood drawn during a study visit and stored at $-80^{\circ} \mathrm{C}$. Sputum was induced as previously described [11] and stored at $-80^{\circ} \mathrm{C}$. Ninety-two inflammation-related proteins were analyzed in the serum and sputum samples using the Olink Inflammation panel (Olink Proteomics, Uppsala, Sweden; Supplementary Table 1). In short, the method was based on proximity extension assay technology: 92 antibody probe pairs were bound to their specific target protein, forming a polymerase chain reaction target sequence through proximity-dependent DNA polymerization that was detected and quantified using a standard real-time polymerase chain reaction [12]. The output was normalized in 2 steps and presented as the relative semiquantitative normalized protein expression (NPX) unit. Finally, the normalized protein expression data were $\log _{2}$ transformed. For sputum samples, the hook effect was ruled out after analyzing undiluted and diluted samples. Protein interactions and 
biological functions were investigated using the STRING database [13].

Serum angiotensin-converting enzyme 2 (ACE2) levels were measured by a human enzyme-linked immunosorbent assay kit (ELISA) (Invitrogen). The procedure was performed according to the manufacturer's instructions.

\section{Data analysis}

Categorical variables are reported as frequencies and proportions. Continuous variables are presented as the medians (interquartile ranges [IQRs]; p25, p75). To compare demographic and clinical variables between groups, the chi-square test or Fisher's exact test was used for each categorical variable, as appropriate. For quantitative variables, the nonparametric MannWhitney $\mathrm{U}$ test was employed. Linear regression was also performed. Multivariate logistic regression analyses (with backward stepwise elimination) were carried out. We entered into the model variables associated in bivariate analysis with a p-value $<0.20$, excluding those that were collinear with other factors. Statistical significance was set at $\mathrm{p}<0.05$, and the statistical analyses were performed using SPSS 24.0 software (SPSS Inc., Chicago, IL, USA). Graphics were generated with GraphPad Prism 6 software (GraphPad Software, La Jolla, CA, USA).

\section{RESULTS}

A total of 108 patients were included in this study. Of them, $46.2 \%$ had a severe COVID-19. Table 1 shows the patient characteristics according to COVID-19 severity. Statistical differences were observed when comparing male sex and body mass index. However, no differences with regard to smoking history, days of hospitalization or other comorbidities or chronic treatments were found.

Table 2 shows the analytical and biomarker parameters according to COVID-19 severity. Significant differences in serum levels of glucose and creatinine were detected but no differences in ACE2. In relation to biomarkers, only 6 serum and 1 sputum biomarkers showed differences. All of them, except C-X3-C motif chemokine ligand 1 (CX3CL1), were elevated in patients with severe disease. After analyzing serum biomarkers, direct interactions between interleukin (IL)-18 and CX3C chemokine receptor 1 (CX3CL1), especially IL6 with both IL18 and osteoprotegerin (OPG, also known as TNFRSF11B), were predicted by STRING analysis (Supplementary Figure 1).

Table 3 provides information about the tests that were performed. A lower DLCO value, a lower 6MWT distance and pathologic CT findings were significantly associated with the severe COVID-19.

According to multivariate analysis, factors associated with severity were DLCO <80\% (OR 5.37; 95\% CI 2.05-14.03; p 0.001) and serum CDCP1 (OR 3.85; 95\% CI 1.46-10.17; $\mathrm{p}=0.006$ ).

Because a relationship between CDCP1 and the profibrotic cytokine TGFb1 has been described [14], we evaluated this relationship in both serum and sputum samples. Regardless of severity, no differences in serum samples were observed (data not shown). However, there were significant differences in induced sputum samples between cases of mild/moderate and severe disease ( $\mathrm{p}<0.0001$ for both) (Supplementary Figure 2). No differences in serum CDCP1 values according to severity or days since symptom onset were found (Supplementary Figure 3).

Finally, after testing relationships between biomarkers in the serum and induced sputum samples, there were significant associations for 19 proteins (Figure 1). Variables with a p value $<0.01$ were interleukin (IL) 5 (p $=0.0001)$, IL33 ( $\mathrm{p}=0.0001)$, IL12B $(\mathrm{p}=0.0005)$, neurotrophin $3(\mathrm{NT} 3)(\mathrm{p}=0.002)$, sirtuin2 $(\mathrm{SIRT} 2)(\mathrm{p}=$ $0.005)$, fibroblast growth Factor 23 (FGF23) $(p=0.005)$, IL17 ( $\mathrm{p}=0.007)$, signal transducing adapter molecule 1 (STAM) $(\mathrm{p}=0.007)$, monocyte chemoattractant protein 2 (MCP2; also known as CCL8) $(\mathrm{p}=0.008)$, and MCP1 (also known as CCL2) $(\mathrm{p}=0.009)$. Direct interactions between cytokines (IL5, IL12B, IL17, IL33) and especially between chemokines (MCP1/CCL2 and MCP2/CCL8) were predicted by STRING analysis (Supplementary Figure 1).

\section{DISCUSSION}

We screened a large panel of biomarkers in serum and induced sputum samples from individuals who had recovered from COVID-19 to investigate post-COVID19 lung sequelae. Although the SARS [15] and MERS [16] outbreaks affected far fewer people than the current COVID-19 pandemic, it is important to note that up to $33 \%$ of patients with MERS [4] and 62\% with SARS [17] developed pulmonary fibrosis. Unlike SARS [18] and MERS [19], COVID-19 appears to affect not only the respiratory system but also multiple other systems [20].

Elevated levels of cytokines such as IL1B, IL7, IL8, IL9, and IL10, monocyte chemoattractant protein and tumor necrosis factor (TNF), among others, in COVID19 have been reported and elevated proinflammatory cytokine levels have been found to correlate with disease severity [21]. Similarly, elevated IL1, IL6, 
Table 1. Characteristics of COVID-19 survivors according to disease severity.

\begin{tabular}{|c|c|c|c|c|}
\hline & $\begin{array}{l}\text { All of them } \\
\quad(n=108)\end{array}$ & $\begin{array}{l}\text { Mild/moderate } \\
\quad(n=58)\end{array}$ & $\begin{array}{c}\text { Severe } \\
(\mathbf{n}=\mathbf{5 0})\end{array}$ & $P$ value \\
\hline Age in years, median $(\mathrm{p} 25 ; \mathrm{p} 75)$ & $55.0(49.0 ; 62.0)$ & $53.5(45.0 ; 61.0)$ & $56.5(51.0 ; 63.0)$ & 0.092 \\
\hline Male sex, n (\%) & $69(63.9)$ & $31(53.4)$ & $38(76.0)$ & 0.015 \\
\hline Caucasian, n (\%) & $94(87.0)$ & $50(86.2)$ & $44(88.0)$ & 0.782 \\
\hline Never smoker history, $\mathrm{n}(\%)$ & $66(61.1)$ & $40(69.0)$ & $26(52.0)$ & 0.071 \\
\hline BMI, median (p25; p75) & $27.9(25.9 ; 30.9)$ & $27.4(24.5 ; 30.1)$ & $28.0(26.1 ; 31.2)$ & 0.033 \\
\hline \multicolumn{5}{|l|}{ Comorbidities } \\
\hline Cardiovascular disease, $\mathrm{n}(\%)$ & $5(4.6)$ & $2(3.4)$ & $3(6.0)$ & 0.661 \\
\hline Hypertension, n (\%) & $27(25.0)$ & $11(19.0)$ & $16(32.0)$ & 0.119 \\
\hline Diabetes mellitus, n (\%) & $12(11.2)$ & $3(5.3)$ & $9(18.0)$ & 0.062 \\
\hline Chronic renal failure, $\mathrm{n}(\%)$ & $2(1.8)$ & $0(0)$ & $2(4.0)$ & 0.212 \\
\hline Chronic aspirin use, n (\%) & $4(3.7)$ & $1(1.7)$ & $3(6.0)$ & 0.241 \\
\hline Chronic statin use, $\mathrm{n}(\%)$ & $12(12.0)$ & $5(8.6)$ & $8(16.0)$ & 0.240 \\
\hline Chronic ACE/ARA-II use, n (\%) & $19(17.5)$ & $8(13.8)$ & $11(22.0)$ & 0.264 \\
\hline \multicolumn{5}{|c|}{ SARS-CoV-2 data during hospitalization admission } \\
\hline Days of hospitalization, median (p25; p75) & $7.5(6.0 ; 10.0)$ & $8.0(6.0 ; 10.2)$ & $7.0(5.6 ; 10.0)$ & 0.975 \\
\hline
\end{tabular}

Table 2. Analytical and biomarker characteristics among COVID-19 survivors according to disease severity.

\begin{tabular}{|c|c|c|c|c|}
\hline & $\begin{array}{l}\text { All of them } \\
(n=108)\end{array}$ & $\begin{array}{l}\text { Mild/moderate } \\
\quad(\mathrm{n}=58)\end{array}$ & $\begin{array}{c}\text { Severe } \\
(\mathbf{n}=50)\end{array}$ & $P$ value \\
\hline \multicolumn{5}{|c|}{ Serum parameters, median (p25; p75) } \\
\hline WBC count, cells $/ \mu \mathrm{L}$ & $6.1(5.1 ; 6.6)$ & $6.01(5.0 ; 6.5)$ & $6.2(5.3 ; 6.7)$ & 0.299 \\
\hline Glucose, $\mathbf{m g} / \mathrm{dL}$ & $95.0(90.0 ; 111.0)$ & $93.0(87.5 ; 101.0)$ & $100.5(94.0 ; 117.7)$ & 0.002 \\
\hline Creatinine, $\mathrm{mg} / \mathrm{dL}$ & $0.8(0.7 ; 0.9)$ & $0.8(07 ; 0.9)$ & $0.9(0.8 ; 1.0)$ & 0.048 \\
\hline $\mathrm{ACE} 2, \mathrm{ng} / \mathrm{mL}$ & $2.4(0.8 ; 11.4)$ & $2.5(0.7 ; 12.2)$ & $2.2(0.8 ; 10.8)$ & 0.803 \\
\hline $\mathrm{ALT}, \mathrm{UI} / \mathrm{L}$ & $22.0(17.0 ; 33.0)$ & $24.0(16.0 ; 33.0)$ & $22.0(17.0 ; 32.2)$ & 0.915 \\
\hline AST, UI/L & $22.0(19.0 ; 26.0)$ & $23.0(19.0 ; 27.0)$ & $22.0(19.7 ; 32.2)$ & 0.268 \\
\hline LDH, UI/L & $189.0(170.0 ; 218.0)$ & $187.0(171.0 ; 225.5)$ & $193.5(168.5 ; 216.5)$ & 0.891 \\
\hline CRP g/dL & $3.3(1.0 ; 4.0)$ & $3.9(1.0 ; 4.0)$ & $3.1(1.0 ; 4.0)$ & 0.875 \\
\hline \multicolumn{5}{|c|}{ Serum biomarkers, median (P25; p75) } \\
\hline CDCP1 & $2.5(2.0 ; 2.9)$ & $2.3(2.0 ; 2.8)$ & $2.8(2.3 ; 3.0)$ & 0.001 \\
\hline OPG & $9.9(9.7 ; 10.0)$ & $9.8(9.7 ; 10.0)$ & $10.0(0.8 ; 10.1)$ & $\mathbf{0 . 0 3 4}$ \\
\hline IL6 & $2.0(1.7 ; 2.5)$ & $1.9(1.6 ; 2.4)$ & $2.3(1.8 ; 2.7)$ & 0.014 \\
\hline IL15RA & $1.3(1.1 ; 1.4)$ & $1.2(1.1 ; 1.4)$ & $1.3(1.1 ; 1.5)$ & 0.011 \\
\hline IL18 & $8.6(8.3 ; 8.9)$ & $8.5(8.2 ; 8.8)$ & $8.6(8.5 ; 9.2)$ & 0.005 \\
\hline CX3CL1 & $4.0(3.7 ; 4.2)$ & $3.9(3.7 ; 4.1)$ & $3.1(3.8 ; 4.4)$ & $\mathbf{0 . 0 3 6}$ \\
\hline \multicolumn{5}{|c|}{ Sputum biomarkers, median (P25; p75) } \\
\hline MCP3 & $0.7(0.4 ; 1.4)$ & $0.7(0.4 ; 1.2)$ & $0.9(0.5 ; 2.3)$ & 0.039 \\
\hline
\end{tabular}

Biomarkers are presented as median of the NPX values. Note: ACE2, angiotensin-converting enzyme 2; ALT, Alanine aminotransferase; AST, Aspartate aminotransferase; CDCP1, CUB domain-containing protein 1; CRP, C-reactive protein; CX3CL1, Fractalkine; IL6, Interleukin 6; IL15RA, Interleukin 15 receptor subunit alpha; IL18, Interleukin 18; LDH, Lactate dehydrogenase; MCP3, Monocyte chemotactic protein 3; OPG, Osteoprotegerin; WBC, White blood cell count. 
Table 3. Pulmonary function test and computed tomography among COVID-19 survivors according to disease severity.

\begin{tabular}{|c|c|c|c|c|}
\hline & $\begin{array}{l}\text { All of them } \\
(\mathrm{n}=108)\end{array}$ & $\begin{array}{c}\text { Mild/Moderate } \\
\quad(\mathbf{n}=\mathbf{5 8})\end{array}$ & $\begin{array}{c}\text { Severe } \\
(\mathbf{n}=\mathbf{5 0})\end{array}$ & $P$ value \\
\hline $\begin{array}{l}\text { Days elapsed from symptom onset to } \\
\text { test performance, median }(\mathrm{p} 25 ; \mathrm{p} 75)\end{array}$ & $104.0(90.5 ; 125.0)$ & $104.5(94.7 ; 127.0)$ & $103.0(88.5 ; 121.2)$ & 0.273 \\
\hline \multicolumn{5}{|c|}{ Functional lung parameter and imaging CT } \\
\hline $\begin{array}{l}\mathrm{FVC}(\%), \text { median }(\mathrm{p} 25 ; \mathrm{p} 75) \\
\mathrm{FVC}>80 \%, \mathrm{n}(\%)\end{array}$ & $106.1(93.2 ; 114.0)$ & $\begin{array}{c}105.0(95.0 ; 114.5) \\
53(91.4)\end{array}$ & $\begin{array}{c}107.6(91.0 ; 113.0) \\
47(94.0)\end{array}$ & $\begin{array}{l}0.671 \\
0.722\end{array}$ \\
\hline $\begin{array}{l}\text { FEV1 }(\%), \text { median }(\mathrm{p} 25 ; \mathrm{p} 75) \\
\text { FEV1 }>80 \%, \mathrm{n}(\%)\end{array}$ & $104.5(95.0 ; 113.5)$ & $\begin{array}{c}103.0(94.7 ; 119.0) \\
54(93.1)\end{array}$ & $\begin{array}{c}105.0(95.0 ; 113.0) \\
48(96.0)\end{array}$ & $\begin{array}{l}0.651 \\
0.684\end{array}$ \\
\hline FEV1/FVC ratio, median (p25; p75) & $1.0(0.9 ; 1.0)$ & $1.0(0.9 ; 1.0)$ & $1.0(0.9 ; 1.1)$ & 0.590 \\
\hline $\begin{array}{l}\text { DLCO }(\%), \text { median (p25; p75) } \\
\text { DLCO }<80 \%, \text { n }(\%)\end{array}$ & $79.0(71.5 ; 93.5)$ & $\begin{array}{c}87.0(75.5 ; 100.5) \\
18(34.6)\end{array}$ & $\begin{array}{l}74.5(65.0 ; 81.0) \\
34(65.4)\end{array}$ & $\begin{array}{c}0.001 \\
<0.0001\end{array}$ \\
\hline 6MWT distance, mean $( \pm$ SD $)$ & $557.0(492.6 ; 610.0)$ & $570.0(523.4 ; 632.5)$ & $\begin{array}{c}516.0 \\
(452.7 ; 598.6)\end{array}$ & 0.036 \\
\hline Pathologic CT, n (\%) & $56(52.8)$ & $24(42.1)$ & $32(65.3)$ & 0.017 \\
\hline
\end{tabular}

Note: 6MWT, 6-minute walk test; CT, chest-computed tomography; DLCO, diffusion capacity of the lung for carbon monoxide; FEV1, forced expiratory volume in the first second; FVC, forced vital capacity; SD, Standard deviation.

IL8, IL12, TGFb1, CCL2, CXCL9, and CXCL10 are detected in individuals with severe SARS [22]. Although serum proinflammatory cytokines (IL6, IL18) were detected in severe cases, we did not observe differences after comparing patients with mild/moderate and severe cases of COVID-19 in multivariate analysis, suggesting that differences do not persist after recovery. In fact, multivariate analysis only showed differences in serum levels of CDCP1. To our knowledge, no data have been reported about serum CDCP1 and the severity of COVID-19.

CDCP1 (also known as CD318, TRASK, SIMA135, or gp140) is a cell surface glycoprotein expressed in multiple cell types, including lung epithelial cells, hepatocytes, and hematopoietic progenitor cells [14, 23, 24]. CDCP1 is present on interstitial fibroblasts, but not myofibroblasts, in normal lungs and those with idiopathic pulmonary fibrosis [14]. In COVID-19-infected children who developed acute vasculitis, CDCP1 was one of the most significantly upregulated genes [25], but this complication was not observed in our study. The reason for the significant increase in CDCP1 levels in serum, but not in induced sputum samples, is unknown, but increased levels of CDCP1 have been described in patients with autoimmune endocrine diseases [26] and neuroinflammatory states [27], among others. Serum CDCP1 levels in post-COVID patients were lower than those observed in the literature in healthy controls $(3.18$ NPX) [27].

Microinjuries to the bronchial and/or alveolar epithelium cause the release of growth factors, such as
$\mathrm{TGFb}$, which has profibrotic potential, leading to the loss of respiratory capacity $[14,28]$. TGFb1 overproduction has been recognized as the most relevant factor related to the progression of pulmonary fibrosis [29]. Shen et al. [30] proposed that the cytokine storm and pathogenesis of COVID-19 are consequence of an unbalanced cytokine network due to increased TGFb activity. These same authors [30] considered that many of the clinical manifestations of COVID-19 (fatigue, dry cough, loss of olfactory and taste, etc.) are related to an increase in TGFb activity. For these reasons, $\mathrm{TGFb}$ has been proposed as a therapeutic target for COVID-19 [31]. In vitro, TGFb1 decreases CDCP1 expression. CDCP1-depleted cells show upregulation of collagen $\mathrm{V}$ and smooth muscle actin (SMA) and further strong enhancement of the effects of TGFb1 on collagen III, collagen V, and SMA [14]. Some authors have reported that CDCP1 is one of the main proteins downregulated by TGFb1 [32], and it has been suggested that CDCP1 is a negative regulator of $\mathrm{TGFb} 1$ signaling in fibroblast-tomyofibroblast differentiation via potential CDCP1/ TGFb1 crosstalk [14]. Hence, we were surprised to observe a positive relationship between CDCP1 and TGFb1, regardless of severity, after analyzing sputum samples. It will be necessary to carry out more studies and, in the longer term, to determine the real impact of these findings.

By evaluating relationships between pulmonary inflammatory status (in induced sputum samples) and serum protein levels, which in our opinion has not been conducted thus far, we observed that only a few 
A

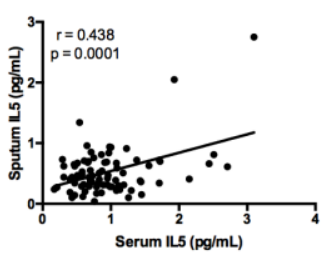

D

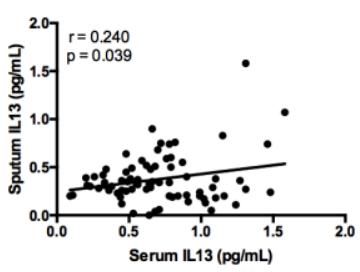

G

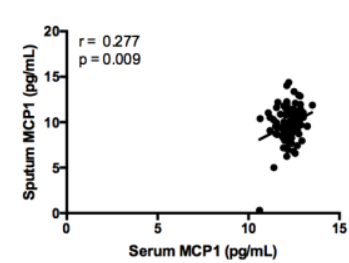

J

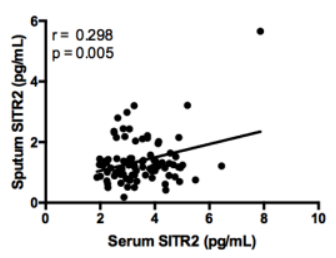

M

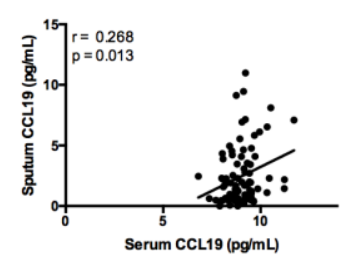

P

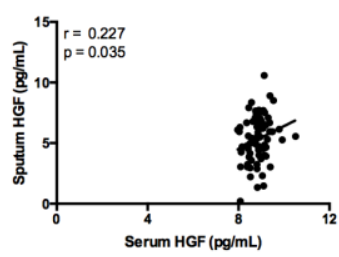

S

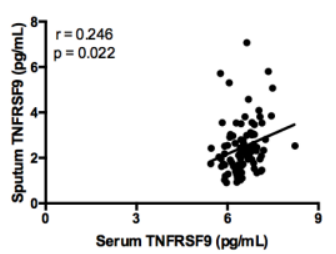

B

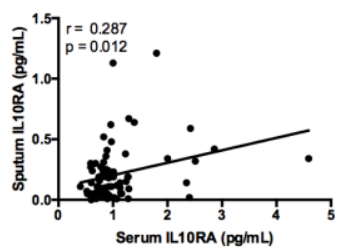

E

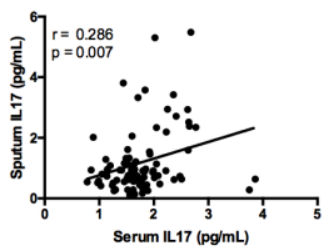

H

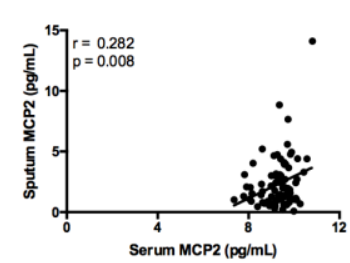

K

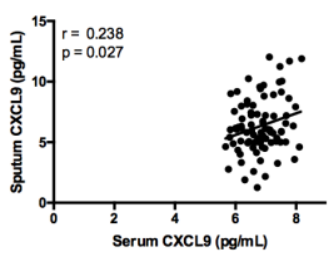

N

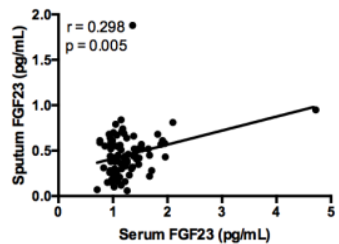

Q

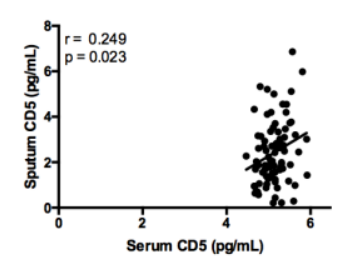

T

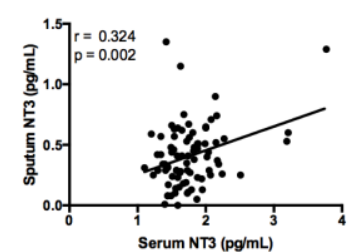

C

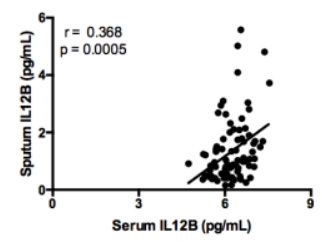

F

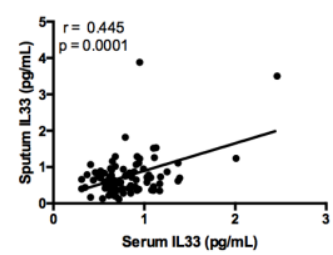

I

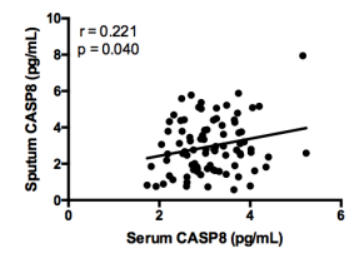

L
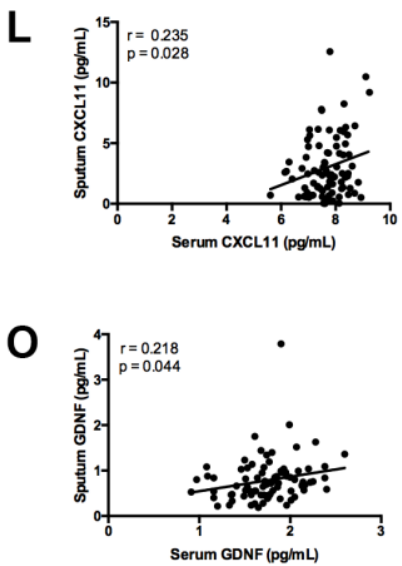

R

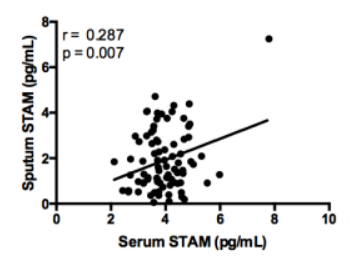

U

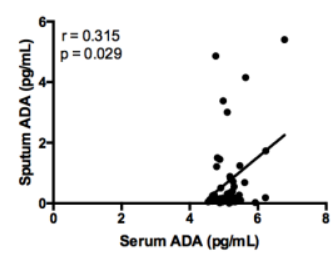

Figure 1. Graphs showing correlation between plasma and induced sputum levels of statistically significant biomarkers. Measurement of: (A) IL5; (B) IL10RA; (C) IL12B; (D) IL13; (E) IL17; (F) IL33; (G) MCP1; (H) MCP2; (I) CASP8; (J) SIRT2; (K) CXCL9; (L) CXCL11; (M) CCL19; (N) FGF23; (O) GDNF; (P) HGF; (Q) CD5; (R) STAM; (S) TNFRSF9; (T) NT3; (U) ADA. The continuous line indicates the correlation between the two variables. 
biomarkers (20\% of all those evaluated) showed a correlation between serum and induced sputum samples. Sputum induction, a noninvasive method, has been used for studying bronchial inflammation in different respiratory diseases [33]. This technique allows for obtaining small sputum macrophages that exhibit features of highly active inflammatory cells and may therefore be used to analyze inflammatory biomarkers [34]. In relation to SARS-CoV-2 infection, we found a statistical correlation for some cytokines and chemokines. This was especially important for CCL2, which showed main interactions with CCL8, IL12B and IL33. According to Szabo et al. [35], CCL2 released by the lung might contribute to lung tissue damage in severe COVID-19 patients, which is why they suggested that CCR2 antagonists be used to prevent lung damage in these patients. Similarly, Blanco-Melo et al. [36] compared postmortem lung samples from males over 60 years of age who did or did not have COVID-19 and observed that the disease induced robust levels of CCL8 and CCL2, among others. This appears to be consistent with the role of monocytes/macrophages in the immunopathogenesis of the disease [36]. Because we observed similar findings and because some of our biomarkers are proinflammatory cytokines and chemokines, further investigations are necessary to understand their potential implications for recovered patients.

Finally, our previous study and other data showed a reduction in DLCO in those recovering from severe COVID-19 [6, 37-39] suggesting the persistence of impaired lung function.

The limitations of our study include the absence of healthy or uninfected people, though it was not the objective of this study because it was focused on evaluating the severity of COVID-19. Another limitation is the relatively small sample size, which might affect the validity of our results and the lack of a control group. In addition, our measures of inflammatory proteins were cross-sectional, and further studies are necessary to investigate the role of CDCP1. However, this study has important strengths, such as the measurement of 92 biomarkers, the use of a noninvasive procedure to collect sputum samples, and comparison between sputum and serum samples.

In conclusion, although the long-term impact of high serum levels of CDCP1 is still unknown, we should be alert to the potential implications for lung disease. For this reason, it is necessary to follow such patients for longer periods of time to detect and adequately treat potential pulmonary sequelae.

\section{AUTHOR CONTRIBUTIONS}

Conceived and designed the analysis: JRB, BJG; Collected the data: JRB, MJCC, FN, IS, CA, EB, LB, LPM, SEP, JGA, JJRC, CA, FGGH, JO, BJG, JU; Analysis tool: EVAE, JRB; Wrote the paper: All the authors.

\section{ACKNOWLEDGMENTS}

We thank all the patients and their families involved in this study, as well as numerous doctors, nurses, and people working together to fight against the SARSCoV-2.

Other collaborators in this project: HU San Pedro (Logroño): L. Romero, MA. Martínez, MF. Espada; HCU Lozano Blesa (Zaragoza): P. Crusells, S. Letona, JM. Guzman, L. Anoro, E. García MM. Rivas, A. Prados, J. Izquierdo, R. Pinilla, A. Lainez, R. García, C. Gonzalez, P. Sanchez), HU Reina Sofía de Murcia: C. Alcade, A. Alcaraz, MJ. Alcaraz, A. Cano, A. Muñoz; HU Burgos: MS. Serrano, E. Reguero, E. Arauzo.

\section{CONFLICTS OF INTEREST}

None of the authors reported conflicts of interest.

\section{FUNDING}

This work was supported by the "Convocatoria de expresiones de interés para la financiación de proyectos de investigación sobre el SARS-CoV-2 y la enfermedad COVID" from Instituto de Salud Carlos III (Project COV20/00401).

\section{REFERENCES}

1. COVID-19 Dashboard by the Center for Systems Science and Engineering (CSSE) at Johns Hopkins University (JHU). https://coronavirus.jhu.edu/map.html

2. Richardson S, Hirsch JS, Narasimhan M, Crawford JM, McGinn T, Davidson KW, Barnaby DP, Becker LB, Chelico JD, Cohen SL, Cookingham J, Coppa K, Diefenbach MA, et al, and the Northwell COVID-19 Research Consortium. Presenting Characteristics, Comorbidities, and Outcomes Among 5700 Patients Hospitalized With COVID-19 in the New York City Area. JAMA. 2020; 323:2052-9. https://doi.org/10.1001/jama.2020.6775 PMID:32320003

3. Nalbandian A, Sehgal K, Gupta A, Madhavan MV, McGroder C, Stevens JS, Cook JR, Nordvig AS, Shalev D, Sehrawat TS, Ahluwalia N, Bikdeli B, Dietz D, et al. 
Post-acute COVID-19 syndrome. Nat Med. 2021; 27:601-15.

https://doi.org/10.1038/s41591-021-01283-z

PMID:33753937

4. Das KM, Lee EY, Singh R, Enani MA, Al Dossari K, Van Gorkom K, Larsson SG, Langer RD. Follow-up chest radiographic findings in patients with MERS-CoV after recovery. Indian J Radiol Imaging. 2017; 27:342-9.

https://doi.org/10.4103/ijri.IJRI 46916

PMID:29089687

5. Antonio GE, Wong KT, Hui DS, Wu A, Lee $N$, Yuen $E H$, Leung $C B$, Rainer TH, Cameron $P$, Chung SS, Sung JJ, Ahuja AT. Thin-section CT in patients with severe acute respiratory syndrome following hospital discharge: preliminary experience. Radiology. 2003; 228:810-5. https://doi.org/10.1148/radiol.2283030726 PMID:12805557

6. Blanco JR, Cobos-Ceballos MJ, Navarro F, Sanjoaquin I, Arnaiz de Las Revillas F, Bernal E, Buzon-Martin L, Viribay M, Romero L, Espejo-Perez S, Valencia B, Ibañez $D$, Ferrer-Pargada D, et al. Pulmonary long-term consequences of COVID-19 infections after hospital discharge. Clin Microbiol Infect. 2021; 27:892-6.

https://doi.org/10.1016/i.cmi.2021.02.019

PMID:33662544

7. Report of the WHO-China Joint Mission on Coronavirus Disease. 2019.

https://www.who.int/docs/default-

source/coronaviruse/who-china-joint-mission-oncovid-19-final-report

8. Hennus MP, van Vught AJ, Brabander M, Brus F, Jansen $\mathrm{NJ}$, Bont $\amalg$. Mechanical ventilation drives inflammation in severe viral bronchiolitis. PLoS One. 2013; 8:e83035. https://doi.org/10.1371/journal.pone.0083035 PMID:24349427

9. ATS Committee on Proficiency Standards for Clinical Pulmonary Function Laboratories. ATS statement: guidelines for the six-minute walk test. Am J Respir Crit Care Med. 2002; 166:111-7.

https://doi.org/10.1164/ajrccm.166.1.at1102 PMID:12091180

10. Ding $\mathrm{X}, \mathrm{Xu} J$, Zhou J, Long $\mathrm{Q}$. Chest $\mathrm{CT}$ findings of COVID-19 pneumonia by duration of symptoms. Eur J Radiol. 2020; 127:109009.

https://doi.org/10.1016/j.ejrad.2020.109009

PMID: $\underline{32325282}$

11. Djukanović R, Sterk PJ, Fahy JV, Hargreave FE. Standardised methodology of sputum induction and processing. Eur Respir J Suppl. 2002 (Suppl 37); $37: 1 s-2 s$

https://doi.org/10.1183/09031936.02.00000102 PMID:12361359
12. Assarsson $E$, Lundberg $M$, Holmquist $G$, Björkesten J, Thorsen SB, Ekman D, Eriksson A, Rennel Dickens E, Ohlsson S, Edfeldt G, Andersson AC, Lindstedt P, Stenvang J, et al. Homogenous 96-plex PEA immunoassay exhibiting high sensitivity, specificity, and excellent scalability. PLoS One. 2014; 9:e95192.

https://doi.org/10.1371/journal.pone.0095192 PMID:24755770

13. Szklarczyk D, Gable AL, Lyon D, Junge A, Wyder S, Huerta-Cepas J, Simonovic M, Doncheva NT, Morris JH, Bork P, Jensen LJ, Mering CV. STRING v11: proteinprotein association networks with increased coverage, supporting functional discovery in genome-wide experimental datasets. Nucleic Acids Res. 2019; 47:D607-13.

https://doi.org/10.1093/nar/gky1131 PMID:30476243

14. Noskovičová N, Heinzelmann K, Burgstaller G, Behr J, Eickelberg $O$. Cub domain-containing protein 1 negatively regulates TGF- $\beta$ signaling and myofibroblast differentiation. Am J Physiol Lung Cell Mol Physiol. 2018; 314:L695-707.

https://doi.org/10.1152/ajplung.00205.2017 PMID:29351434

15. WHO. Cumulative number of reported probable cases of SARS.

https://www.who.int/csr/sars/country/2003 $07 \quad 11$ Len/

16. WHO. Middle East respiratory syndrome coronavirus (MERS-CoV). https://www.who.int/emergencies/mers-cov/en/

17. Hui DS, Joynt GM, Wong KT, Gomersall CD, Li TS, Antonio G, Ko FW, Chan MC, Chan DP, Tong MW, Rainer TH, Ahuja AT, Cockram CS, Sung JJ. Impact of severe acute respiratory syndrome (SARS) on pulmonary function, functional capacity and quality of life in a cohort of survivors. Thorax. 2005; 60:401-9. https://doi.org/10.1136/thx.2004.030205 PMID:15860716

18. Zhang Y, Li J, Zhan Y, Wu L, Yu X, Zhang W, Ye L, Xu S, Sun R, Wang $Y$, Lou J. Analysis of serum cytokines in patients with severe acute respiratory syndrome. Infect Immun. 2004; 72:4410-5.

https://doi.org/10.1128/IAI.72.8.4410-4415.2004 PMID:15271897

19. Mahallawi WH, Khabour OF, Zhang Q, Makhdoum HM, Suliman BA. MERS-CoV infection in humans is associated with a pro-inflammatory Th1 and Th17 cytokine profile. Cytokine. 2018; 104:8-13. https://doi.org/10.1016/i.cyto.2018.01.025 PMID:29414327

20. Chen T, Wu D, Chen H, Yan W, Yang D, Chen G, Ma K, Xu D, Yu H, Wang H, Wang T, Guo W, Chen J, et al. 
Clinical characteristics of 113 deceased patients with coronavirus disease 2019: retrospective study. BMJ. 2020; 368:m1091.

https://doi.org/10.1136/bmj.m1091 PMID:32217556

21. Huang $C$, Wang $Y$, Li $X$, Ren L, Zhao J, Hu Y, Zhang L, Fan G, Xu J, Gu X, Cheng Z, Yu T, Xia J, et al. Clinical features of patients infected with 2019 novel coronavirus in Wuhan, China. Lancet. 2020; 395:497-506. https://doi.org/10.1016/S0140-6736(20)30183-5 PMID:31986264

22. Liu J, Zheng $X$, Tong $Q$, Li W, Wang B, Sutter K, Trilling $M$, Lu M, Dittmer U, Yang D. Overlapping and discrete aspects of the pathology and pathogenesis of the emerging human pathogenic coronaviruses SARSCoV, MERS-CoV, and 2019-nCoV. J Med Virol. 2020; 92:491-4.

https://doi.org/10.1002/imv.25709

PMID:32056249

23. Bühring HJ, Kuçi S, Conze T, Rathke G, Bartolović K, Grünebach F, Scherl-Mostageer M, Brümmendorf TH, Schweifer N, Lammers R. CDCP1 identifies a broad spectrum of normal and malignant stem/progenitor cell subsets of hematopoietic and nonhematopoietic origin. Stem Cells. 2004; 22:334-43.

https://doi.org/10.1634/stemcells.22-3-334 PMID:15153610

24. Hooper JD, Zijlstra A, Aimes RT, Liang H, Claassen GF, Tarin D, Testa JE, Quigley JP. Subtractive immunization using highly metastatic human tumor cells identifies SIMA135/CDCP1, a $135 \mathrm{kDa}$ cell surface phosphorylated glycoprotein antigen. Oncogene. 2003; 22:1783-94.

https://doi.org/10.1038/sj.onc.1206220

PMID:12660814

25. Gruber CN, Patel RS, Trachtman R, Lepow L, Amanat F, Krammer F, Wilson KM, Onel K, Geanon D, Tuballes K, Patel M, Mouskas K, O'Donnell T, et al. Mapping systemic inflammation and antibody responses in multisystem inflammatory syndrome in children (MISC). Cell. 2020; 183:982-995.e14.

https://doi.org/10.1016/i.cell.2020.09.034 PMID:32991843

26. Magnusson L, Espes D, Casas R, Carlsson PO. Increased Plasma Levels of the Co-stimulatory Proteins CDCP1 and SLAMF1 in Patients With Autoimmune Endocrine Diseases. Front Immunol. 2020; 11:1916.

https://doi.org/10.3389/fimmu.2020.01916 PMID: $\underline{2983115}$

27. Palada V, Ahmed AS, Freyhult E, Hugo A, Kultima K, Svensson $\mathrm{Cl}$, Kosek E. Elevated inflammatory proteins in cerebrospinal fluid from patients with painful knee osteoarthritis are associated with reduced symptom severity. J Neuroimmunol. 2020; 349:577391. https://doi.org/10.1016/i.jneuroim.2020.577391 PMID: $\underline{32987275}$

28. Shukla A, Meisler N, Cutroneo KR. Perspective article: transforming growth factor-beta: crossroad of glucocorticoid and bleomycin regulation of collagen synthesis in lung fibroblasts. Wound Repair Regen. 1999; 7:133-40. https://doi.org/10.1046/i.1524-475X.1999.00133.x PMID: $\underline{10417748}$

29. Chen RR, Li YJ, Chen JJ, Lu CL. A review for natural polysaccharides with anti-pulmonary fibrosis properties, which may benefit to patients infected by 2019-nCoV. Carbohydr Polym. 2020; 247:116740. https://doi.org/10.1016/j.carbpol.2020.116740 PMID: $\underline{32829859}$

30. Shen WX, Luo RC, Wang JQ, Chen ZS. Features of cytokine storm identified by distinguishing clinical manifestations in COVID-19. Front Public Health. 2021; 9:671788.

https://doi.org/10.3389/fpubh.2021.671788 PMID: $\underline{34109148}$

31. Chen W. A potential treatment of COVID-19 with TGF- $\beta$ blockade. Int J Biol Sci. 2020; 16:1954-5. https://doi.org/10.7150/ijbs.46891 PMID:32398962

32. Heinzelmann K, Noskovičová N, Merl-Pham J, Preissler G, Winter H, Lindner M, Hatz R, Hauck SM, Behr J, Eickelberg $O$. Surface proteome analysis identifies platelet derived growth factor receptor-alpha as a critical mediator of transforming growth factor-betainduced collagen secretion. Int J Biochem Cell Biol. 2016; 74:44-59.

https://doi.org/10.1016/i.biocel.2016.02.013 PMID:26905437

33. Eickmeier $\mathrm{O}$, Huebner $\mathrm{M}$, Herrmann $\mathrm{E}$, Zissler $\mathrm{U}$, Rosewich M, Baer PC, Buhl R, Schmitt-Grohé S, Zielen $S$, Schubert R. Sputum biomarker profiles in cystic fibrosis (CF) and chronic obstructive pulmonary disease (COPD) and association between pulmonary function. Cytokine. 2010; 50:152-7. https://doi.org/10.1016/i.cyto.2010.02.004 PMID:20181491

34. Frankenberger $M$, Menzel $M$, Betz $R$, Kassner $G$, Weber $N$, Kohlhäufl $M$, Häussinger $K$, Ziegler-Heitbrock $L$. Characterization of a population of small macrophages in induced sputum of patients with chronic obstructive pulmonary disease and healthy volunteers. Clin Exp Immunol. 2004; 138:507-16.

https://doi.org/10.1111/j.1365-2249.2004.02637.x PMID:15544629

35. Szabo PA, Dogra P, Gray II, Wells SB, Connors TJ, Weisberg SP, Krupska I, Matsumoto R, Poon MM, Idzikowski E, Morris SE, Pasin C, Yates AJ, et al. Longitudinal profiling of respiratory and systemic 
immune responses reveals myeloid cell-driven lung inflammation in severe COVID-19. Immunity. 2021; 54:797-814.e6.

https://doi.org/10.1016/i.immuni.2021.03.005

PMID:33765436

36. Blanco-Melo D, Nilsson-Payant BE, Liu WC, Uhl S, Hoagland D, Møller R, Jordan TX, Oishi K, Panis M, Sachs D, Wang TT, Schwartz RE, Lim JK, et al. Imbalanced host response to SARS-CoV-2 drives development of COVID-19. Cell. 2020; 181:1036-45.e9. https://doi.org/10.1016/i.cell.2020.04.026

PMID:32416070

37. Huang $Y$, Tan $C$, Wu J, Chen $M$, Wang Z, Luo L, Zhou $X$, Liu X, Huang X, Yuan S, Chen C, Gao F, Huang J, et al. Impact of coronavirus disease 2019 on pulmonary function in early convalescence phase. Respir Res. 2020; 21:163. https://doi.org/10.1186/s12931-020-01429-6

PMID:32600344

38. Zhao YM, Shang YM, Song WB, Li QQ, Xie H, Xu QF, Jia JL, Li LM, Mao HL, Zhou XM, Luo H, Gao YF, Xu AG. Follow-up study of the pulmonary function and related physiological characteristics of COVID-19 survivors three months after recovery. EClinicalMedicine. 2020; 25:100463.

https://doi.org/10.1016/j.eclinm.2020.100463 PMID:32838236

39. Qin W, Chen S, Zhang Y, Dong F, Zhang Z, Hu B, Zhu Z, Li F, Wang $X$, Wang $Y$, Zhen K, Wang J, Wan $Y$, et al. Diffusion capacity abnormalities for carbon monoxide in patients with COVID-19 at 3-month follow-up. Eur Respir J. 2021; 58:2003677.

https://doi.org/10.1183/13993003.03677-2020

PMID:33574077 


\section{SUPPLEMENTARY MATERIALS}

\section{Supplementary Figures}
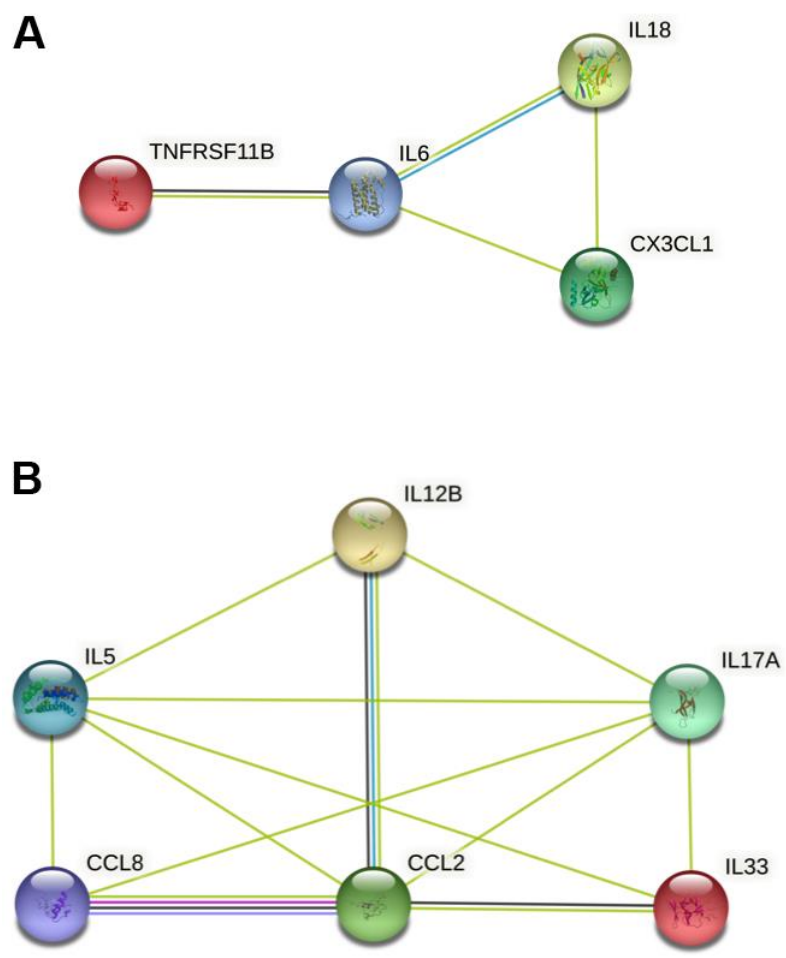

Supplementary Figure 1. STRING analysis was conducted to map predicted interactions. (A) The resulting network shows several clusters, especially from IL6 with both IL18 and osteoprotegerin/tumor necrosis factor receptor superfamily member 11B (OPG/TNFRSF11B); (B) the resulting network shows several clusters, especially between MCP1/CCL2 and MCP2/CCL8. 

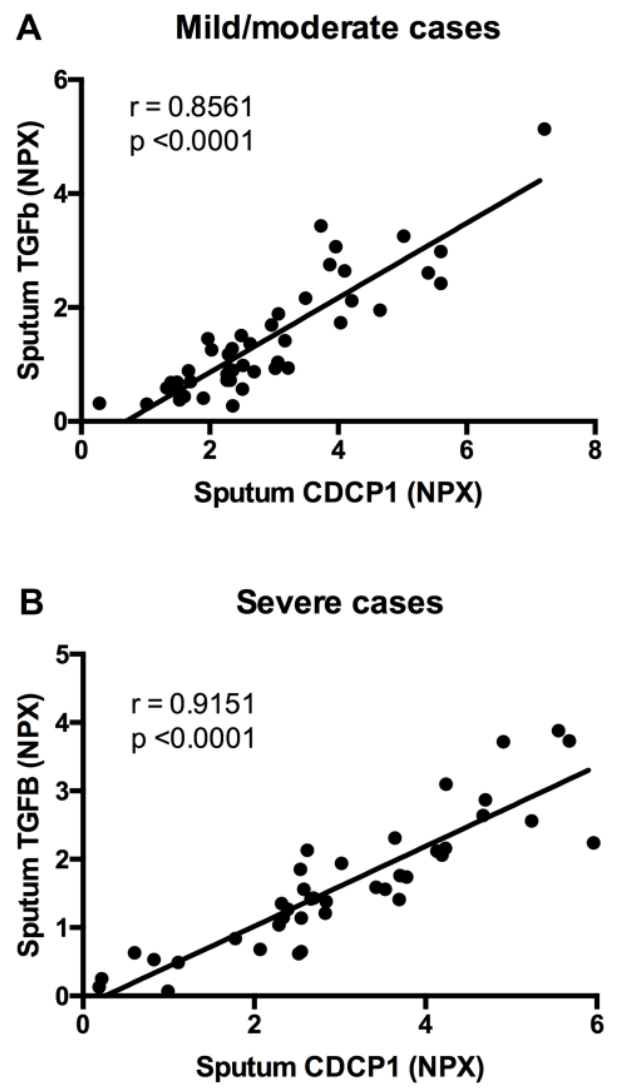

Supplementary Figure 2. Graphs showing the correlation between CDCP1 and TGFb1/L levels in sputum samples from patients with $\mathrm{mild} /$ moderate $(\mathbf{A})$ and severe disease (B). The continuous line indicates the correlation between the two variables. 

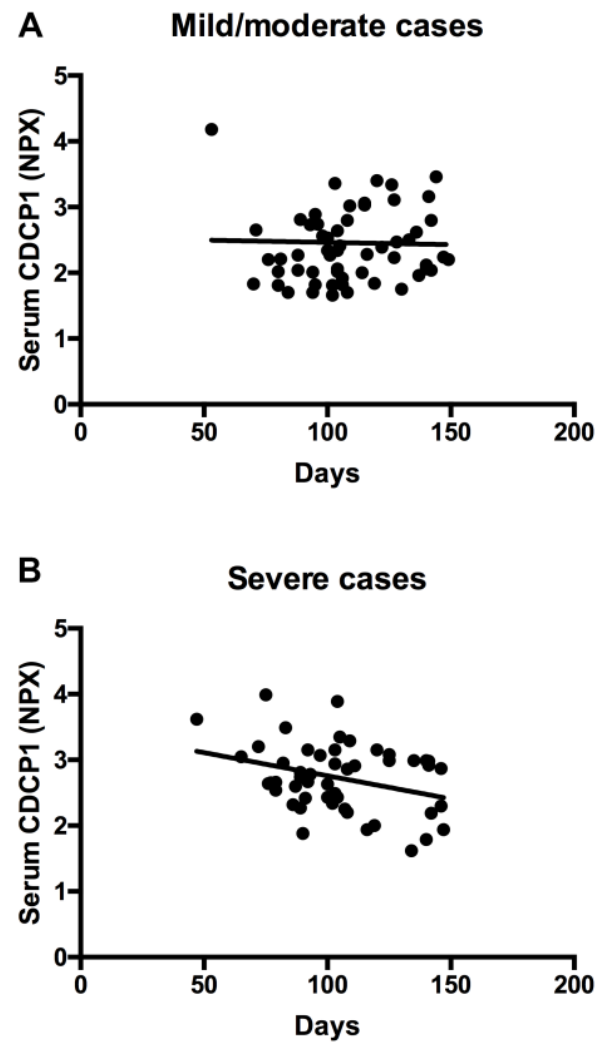

Supplementary Figure 3. Graphs showing the correlation between serum CDCP1 and days since symptom onset in patients with $\mathrm{mild} /$ moderate (A) and severe disease (B). The continuous line indicates the correlation between the two variables. 


\section{Supplementary Table}

Supplementary Table 1. Olink ${ }^{\circledast}$ inflammation panel - list of proteins measured in this study.

\begin{tabular}{|c|c|}
\hline $\begin{array}{l}\text { Adenosine deaminase (ADA) } \\
\text { Artemin (ARTN) } \\
\text { Axin-1 (AXIN1) } \\
\text { Beta-nerve growth factor (Beta-NGF) } \\
\text { Caspase } 8 \text { (CASP-8) } \\
\text { C-C motif chemokine } 4 \text { (CCL4) } \\
\text { C-C motif chemokine 19 (CCL19) } \\
\text { C-C motif chemokine } 20 \text { (CCL20) } \\
\text { C-C motif chemokine 23 (CCL23) } \\
\text { C-C motif chemokine 25 (CCL25) } \\
\text { C-C motif chemokine 28 (CCL28) } \\
\text { CD40L receptor (CD40) } \\
\text { CUB domain-containing protein 1 (CDCP1) } \\
\text { C-X-C motif chemokine 1 (CXCL1) } \\
\text { C-X-C motif chemokine } 5 \text { (CXCL5) } \\
\text { C-X-C motif chemokine 6 (CXCL6) } \\
\text { C-X-C motif chemokine } 9 \text { (CXCL9) } \\
\text { C-X-C motif chemokine 10 (CXCL10) } \\
\text { C-X-C motif chemokine 11 (CXCL11) } \\
\text { Cystatin D (CST5) } \\
\text { Delta and Notch-like epidermal growth factor-related receptor } \\
\text { (DNER) } \\
\text { Eotaxin-1 (CCL11) } \\
\text { Eukaryotic translation initiation factor 4E-binding protein 1 } \\
\text { (4E-BP1) } \\
\text { Fibroblast growth factor } 5 \text { (FGF-5) } \\
\text { Fibroblast growth factor 19 (FGF-19) } \\
\text { Fibroblast growth factor 21 (FGF-21) } \\
\text { Fibroblast growth factor 23 (FGF-23) } \\
\text { Fms-related tyrosine kinase } 3 \text { ligand (Flt3L) } \\
\text { Fractalkine (CX3CL1) } \\
\text { Glial cell line-derived neurotrophic factor (GDNF) } \\
\text { Hepatocyte growth factor (HGF) } \\
\text { Interferon gamma (IFN-gamma) } \\
\text { Interleukin-1 alpha (IL-1 alpha) } \\
\text { Interleukin-2 (IL-2) } \\
\text { Interleukin-2 receptor subunit beta (IL-2RB) } \\
\text { Interleukin-4 (IL-4) } \\
\text { Interleukin-5 (IL-5) } \\
\text { Interleukin-6 (IL-6) } \\
\text { Interleukin-7 (IL-7) } \\
\text { Interleukin-8 (IL-8) } \\
\text { Interleukin-10 (IL-10) } \\
\text { Interleukin-10 receptor subunit alpha (IL-10RA) } \\
\text { Interleukin-10 receptor subunit beta (IL-10RB) } \\
\text { Interleukin-12 subunit beta (IL-12B) } \\
\text { Interleukin-13 (IL-13) } \\
\text { Interleukin-15 receptor subunit alpha (IL-15RA) } \\
\text { Interleukin-17A (IL-17A) } \\
\text { Interleukin-18 (IL-17C) } \\
\text { C.18) }\end{array}$ & 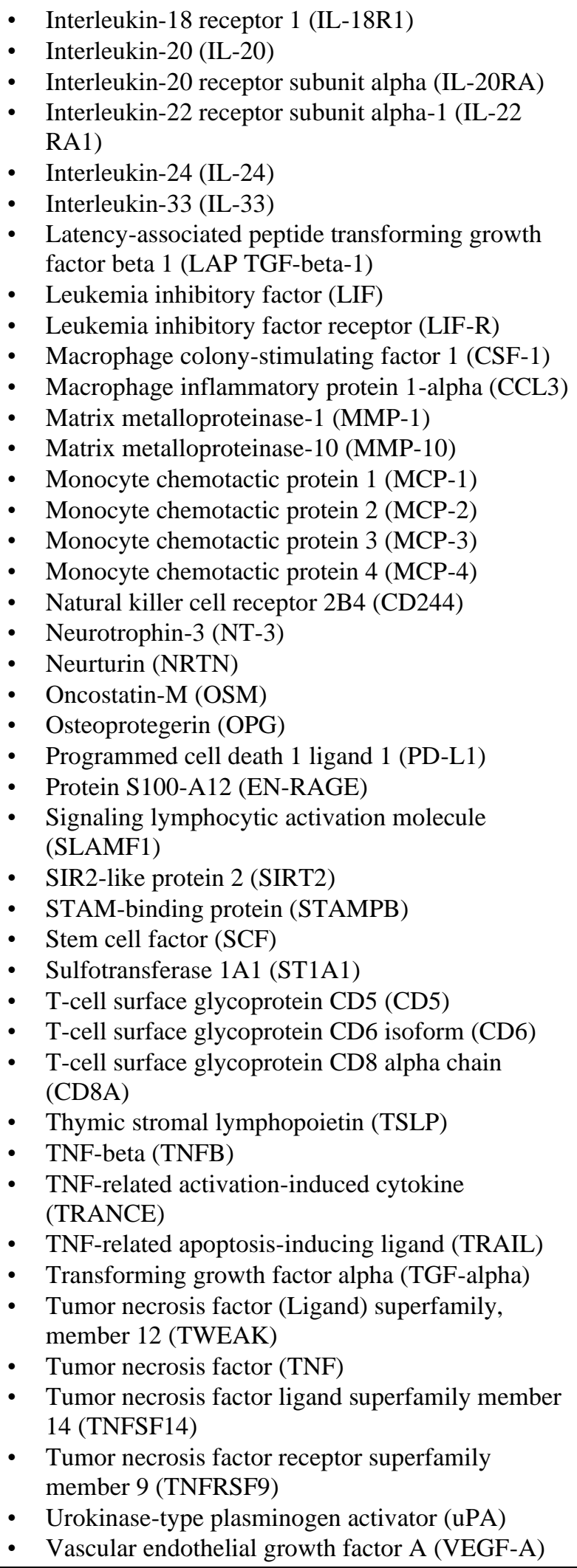 \\
\hline
\end{tabular}

